\title{
SEGREGAÇÃO URBANA E IDENTIDADE CULTURAL: UMA CONTRIBUIÇÃO PARA O ENFRENTAMENTO DA INEFICÁCIA DO DIREITO À MORADIA
}

\author{
Gabriela Macedo de Oliveira Barcelos* \\ Gerardo Clésio Maia Arruda**
}

\section{RESUMO}

Este artigo apresenta a segregação urbana enquanto fenômeno complexo e real no Brasil. É possível ver nas cidades brasileiras contrastes socioeconômicos e culturais na ocupação do espaço urbano. Tem-se como objetivo analisar a formação da identidade dos grupos vulneráveis a partir de sua interação interna e com outros grupos sociais. A metodologia adotada apoiou-se em análise bibliográfica e, também, a partir dos relatos da autora Carolina Maria de Jesus, moradora da favela do Canindé, em São Paulo, autora do livro "Quarto de Despejo". Concluiu-se que a construção falseada da identidade funciona como obstáculo para o exercício de uma cidadania ativa.

Palavras-chave: Urbanização; Segregação; Identidade; Desenvolvimento; Direito à moradia.

\section{URBAN SEGREGATION AND CULTURAL IDENTITY: A CONTRIBUITION TO THE FACING OF THE RIGHT TO HOUSING INEFFICIENCY}

\begin{abstract}
This paper presents urban segregation as a complex and real phenomenon in Brazil. It is possible to see in Brazilian cities socioeconomic and cultural contrasts in the occupation of urban space. The objective is to analyze the formation of the identity of vulnerable groups from their internal interaction and with other social groups. The adopted methodology was based on bibliographic analysis and, also, based on the reports of author Carolina Maria de Jesus, resident of the Canindé favela, in São Paulo, author of the book "Room of Eviction". It was concluded that the false construction of identity acts as an obstacle to the exercise of active citizenship.
\end{abstract}

Keywords: Urbanization; Segregation; Identity; Development; Right to housing.

\section{INTRODUÇÃO}

\author{
Favela oi, favela, \\ Favela que guardo no meu coração \\ Ao recordar com saudade
}

\footnotetext{
* Mestranda em Processo e Direito ao Desenvolvimento pelo Centro Universitário Christus (UNICHRISTUS) com extensão acadêmica no Mestrado em Direitos Humanos da Universidade do Minho (UMinho) em Portugal. Graduada em Direito pela Universidade de Fortaleza (UNIFOR). E-mail: <barcelos-gabriela@hotmail.com>.

*** Doutor e Mestre em Sociologia pela Universidade Federal do Ceará (UFC). Especialista em Geografia e Graduado em Ciências Econômicas pela Universidade Federal do Ceará (UFC). Professor do Programa de PósGraduação em Direito (Mestrado) do Centro Universitário Christus (UNICHRISTUS). Professor Titular da Universidade de Fortaleza (UNIFOR), Ceará (Brasil). E-mail: <clesioarruda@yahoo.com.br>.
} 
A minha felicidade

Favela dos sonhos de amor

E do samba-canção.

(Favela, Francisco Alves, 1936)

A primeira epígrafe acima destaca uma estrofe da letra da música "Favela", de Francisco Alves, de 1936. Vê-se no recorte que as áreas empobrecidas das grandes cidades ainda são apreendidas como um lugar predominantemente lúdico. Neste período, o Brasil passava por um fortalecimento do processo de industrialização e adensamento populacional nas capitais dos Estados, mais intensamente os da região Sudeste.

Um dia sonhei um porvir risonho

E coloquei o meu sonho

Num pedestal bem alto

Não devia e por isso me condeno

Sendo do morro e moreno

Amar a deusa do asfalto.

(A deusa do asfalto, Nelson Gonçalves, 1958)

Duas décadas após, Nelson Gonçalves em sua interpretação da música "Deusa do asfalto" de Adelino Moreira, denota poeticamente que o lugar da alegria, do samba-canção, é apartado do espaço onde as benesses da modernidade se fazem presentes, de sorte que aqueles que desfrutam do bem-estar proporcionado pela cidade moderna constituem uma classe social distinta daqueles que vivem nas ruelas sem saneamento, em habitações construídas com materiais inapropriados, sem estrutura que possibilite a moradia digna.

\footnotetext{
Quem é rico mora na praia,

mas quem trabalha não tem

onde morar

Quem não chora dorme com fome,

mas quem tem nome

joga prata no ar
} 


\section{Ô tempo duro no ambiente, \\ ô tempo escuro na memória, \\ o tempo é quente.}

(Pedras que cantam, Raimundo Fagner, 1991)

No final do século XX, como explicitado na letra da música "Pedras que cantam", de autoria de Dominguinhos e Fausto Nilo, interpretada por Raimundo Fagner, a moradia se colocava como uma grave questão social que demandava políticas públicas de ocupação do solo urbano, que, para além da melhoria da racionalização dos espaços, fossem capazes de enfrentar imperiosamente o déficit habitacional que deixava parcelas da população na condição de moradores de rua.

Atualmente, a segregação urbana é uma realidade que tem suas raízes fincadas em dimensões da sociabilidade que ultrapassam as questões de viés exclusivamente econômico. Com efeito, trata-se de um fenômeno com implicações também culturais, de tal maneira que afeta a vida das pessoas residentes em muitas cidades brasileiras distinguindo os grupos populacionais no concernente ao acesso à moradia, à educação, à saúde, ao trabalho. A questão urbana brasileira, dada sua estrutura consolidada na trajetória do século XX, funciona para a concretização do hiato que separa os indivíduos em seus estilos e condições de sobrevivência e para a construção do fosso que distancia as pessoas na construção de suas identidades socioculturais.

O Desenvolvimento urbano e humano não deve estar atrelado somente ao suprimento das necessidades materiais básicas e da construção de uma infraestrutura de circulação das pessoas e das mercadorias. Para sua efetiva realização, faz-se necessário atentar para a universalização do gozo de liberdades e de direitos. Com efeito, existe uma correlação entre a qualidade e sustentabilidade da democracia das comunidades políticas e as cidades em que a cidadania se exerce de forma mais alargada ou com maiores restrições. Enfim, a discussão da questão urbana se trata de um fenômeno que se entrelaça às várias disciplinas, como a economia, a sociologia e a arquitetura urbana, mas que tem seu efetivo enfrentamento vinculado à ciência política e ao direito.

Faz-se, neste artigo, um esforço para analisar a segregação urbana enquanto elemento essencial na formação das identidades e do desenvolvimento humano. Para tanto, além da pesquisa bibliográfica e documental, adota-se o recurso metodológico da análise da trajetória 
de vida e da experiência existencial com base no relato de sujeito social que construiu suas memórias na realidade vivida na condição de segregado urbano. Tal procedimento metodológico se efetivou a partir da autobiografia de Carolina Maria de Jesus, que publicou, na forma de livro, as suas memórias de moradora de favela e os esforços empreendidos para garantir a sua sobrevivência como moradora em situação de risco.

Carolina Maria de Jesus, era catadora de lixo e moradora da favela do Canindé, em São Paulo, onde residia com seus três filhos, na década de 50. Apesar de sua pouca instrução, escrevia e guardava seus diários, que tempos depois foram compilados na forma de livro, intitulado "Quarto de despejo". A sua publicação decorreu do apoio do jornalista Audálio Dantas, que foi até a favela do Canindé para produzir uma reportagem e teve acesso aos seus manuscritos. A obra foi traduzida para treze idiomas e ganhou notoriedade por ser não só um relato cru da sua realidade como também pela manutenção da escrita simples tornando a narrativa sensível e acessível.

A contribuição de Carolina não se prendeu tão somente à literatura, pois se trata também de uma crítica ao sistema jurídico-político e às políticas públicas. A narrativa da autora trouxe a atenção de muitos para algo que, de tão estranho às suas realidades, parecia não existir; expressou insatisfações e necessidades não só de sua família, mas de um contingente populacional com um modo de vida semelhante. A autora foi porta voz de grupos excluídos e trouxe, com a sua narrativa primária, um olhar humanizado para o "Quarto de despejo", que era a denominação da favela, do espaço descrito no livro.

Além desta seção introdutória, o artigo está dividido, em duas partes, sendo que, na primeira, explicitam-se os contornos teóricos e históricos da segregação urbana; na segunda, busca-se demonstrar a relação que há entre o fenômeno da segregação com a formação das identidades e os efeitos no próprio desenvolvimento humano, ambas trazendo em seu desenvolvimento recortes da obra de Carolina que corroboram com os aspectos teóricos apresentados.

\section{SEGREGAÇÃO URBANA}

A cidade é bem mais do que um espaço geograficamente delimitado e constituído de equipamentos públicos e propriedades particulares, uma vez que sua paisagem reflete os traços culturais de seus grupos populacionais e os interesses em disputa e que constituem a 
comunidade política. $\mathrm{O}$ espaço urbano é marcado pela tessitura das interações sociais que o definem e o transformam, de sorte que se tem um cenário em que tanto a arquitetura quanto seus habitantes são diferentemente estruturados.

A segregação urbana é um fenômeno que diz respeito às divisões de ocupação do espaço urbano alicerçado no perfil socioeconômico dos seus habitantes. Isto conduz a localização de grupos populacionais em áreas distintas e delimitadas, em que no limite dos segmentos tornam-se apartados e imersos em interações endógenas e em interações pontuais com os demais segmentos populacionais que gravitam no seu entorno. Deve ser compreendida na medida de sua complexidade, considerando todos as variáveis intervenientes, tais como a economia e a política (VILLAÇA, 2012).

A comunidade política, que se caracteriza por sua divisão em classes sociais, é também marcada pela divisão na ocupação dos espaços constituintes das suas cidades. As paisagens das cidades brasileiras retratam de forma exemplar a possibilidade de se distinguir os grupos populacionais carentes dos grupos de renda média e dos grupos de renda alta. Uma segmentação que se denota no espaço em que predomina, de um lado, a ausência de pavimentação das ruas, onde becos e ruelas impedem a prestação de serviços públicos de coleta de lixo, do acesso de unidades móveis de saúde e de segurança, a falta de esgotos e canalizações para escoamento de águas das casas e das chuvas, a inexistência de equipamentos de lazer; de outro lado, uma infraestrutura que possibilita a recepção dos serviços públicos e privados de toda a natureza, dada a possibilidade do acesso e circulação de pessoas e mercadorias, além da instalação de equipamentos de segurança, saúde, educação e culturais.

Essa segmentação e qualificação do espaço urbano brasileiro encontra-se enraizada nas mudanças decorrentes do processo de industrialização, que teve seu ápice na década de 1930. Instalou-se uma atmosfera de agitação, afinal a "modernidade" chegava ao Brasil e as cidades deveriam se adequar a esse momento. Para tanto, fazia-se necessário fundamentar na razão as ações e intervenções para tornar o espaço funcional (BARIFOUSE, 2013). Assim, os centros urbanos, principalmente as capitais, passaram a exercer forte atratividade para as famílias das áreas rurais que, devido à escassez de terras para a produção agrícola de subsistência e as péssimas condições de trabalho nas fazendas, demandavam oportunidade de trabalho assalariado. 
O afluxo de correntes migratórias na direção campo-cidades trouxe para os centros urbanos inumeráveis pessoas que não detinham qualificação para o trabalho nas fábricas e nem nas organizações comerciais e de serviços. Constituiu-se um lupenproletariado sem condição de inserção nas atividades de trabalho nas cidades, e que sem condições de arcar com custos de habitação foram-se arranjando em moradias improvisadas, originando os cortiços e os loteamentos periféricos. Estes últimos, constituíam-se em espécies de conjuntos habitacionais, edificados pelos próprios trabalhadores nas cercanias das cidades, em regiões mais afastadas dos centros, não atendidas pelos serviços públicos e destituídas de estrutura básica. Já os cortiços eram moradias coletivas, onde inúmeras famílias dividiam um mesmo imóvel, que nem sempre oferecia condições adequadas de ventilação e higiene.

Registros históricos, acerca da precariedade da moradia dos trabalhadores, nas primeiras décadas do século $\mathrm{XX}$, indicam que era comum encontrar operários que residiam em casas oferecidas pelos donos das fábricas ou que pernoitavam nos próprios ambientes de trabalho. A cessão da moradia constituía parte da remuneração, o que, num contexto de déficit habitacional elevado, funcionava como instrumento de controle. Essa conjuntura era profícua em termos de tensões entre patronos e empregados, sendo frequente o surgimento de eventuais levantes por parte da classe trabalhadora através de movimentos sociais como por exemplo a greve de 1917 em São Paulo (GOHN, 2000).

As inumeráveis áreas nas periferias das cidades de médio e grande porte sem infraestrutura capaz de gerar condições dignas de moradia refletem o fracasso das políticas públicas adotadas na trajetória do processo de industrialização e de urbanização. O Estado brasileiro foi omisso, na medida em que atuou de forma esporádica e descontínua, deixando grande parte do esforço para a solução da moradia sob a responsabilidade da iniciativa privada e dos próprios trabalhadores (BONDUKI, 2011).

A moradia de Carolina, na favela do Canindé, é o protótipo de moradia precária, segregada e improvisada, típica da época. Em uma parte de seus relatos a autora faz o seguinte destaque: “[...] aqui na favela há os que fazem os barracões para residir e os que fazem para alugar. E os aluguéis são 500 a 700,00. E os que fazem barracões para vender. Gasta 4 mil cruzeiros e vendem por 11 mil cruzeiros. Quem fez muitos barracões foi o Tibúrcio." (JESUS, 1997, p. 41).

As ações governamentais que nunca chegaram a concretizar uma política de Estado de longo prazo, e que deixaram à iniciativa privada a construção de casas para fins de 
comercialização e ao trabalhador a alternativa de fazer poupança ou de se submeter a empréstimos com elevadas taxas de juros, refletiram a vontade política que atravessou grande parte do período republicano. Isso conduziu para a concretização das distâncias socioeconômicas que separam de forma abissal as classes sociais no Brasil, como se busca aqui demonstrar esse fenômeno se manifestou na ocupação do espaço urbano. Essa omissão estatal deixou claro que o direito à cidade não alcançava aqueles com recursos limitados, para estes admitia-se somente o direito à ocupação (MARICATO, 2003).

Enfim, a industrialização foi determinante para a definição dos estratos populacionais que se localizariam nos espaços urbanos degradados e sem infraestrutura. Isto porque o crescimento da produção industrial no curto prazo, sem o devido planejamento do poder público na delimitação das áreas de habitação dos trabalhadores e de atendimento das suas necessidades de deslocamento para o local de trabalho e para a satisfação de outras necessidades básicas, levou as cidades brasileiras a compartilharem um processo de expansão desorganizado. Seguiu-se um fluxo de pautas que se distanciavam das reais necessidades populares, pois o que funcionou como variável definidora foram os interesses econômicos de grupos particulares. Tal estratégia levou Milton Santos (2013) a denominar a ocupação do espaço das cidades como sendo uma "urbanização corporativa".

Essa nomenclatura é atribuída ao fenômeno da influência que empresas e corporações exercem sobre o Poder Público na ocasião de sua implantação em determinado lugar, gerando assim consequências locais e por vezes profundas, sentidas mais diretamente pela população de renda mais baixa. Não é exagero afirmar, como se verifica empiricamente e pode ser constatado visualmente, que a "urbanização corporativa" gerou resultados positivos para os grupos populacionais dos andares de cima do topo da pirâmide social, para quem se destinou as áreas arborizadas, com ruas pavimentadas e saneamento, além de infraestrutura de lazer e de serviços públicos e privados.

Algumas das cidades brasileiras consolidaram uma paisagem marcada pelo antagonismo, onde áreas comportam com poucos metros de distâncias condomínios de alto luxo circundados por vielas e habitações degradadas. Um contraste que ressalta a estrutura social brasileira, como indicam Pochmann e Amorim (2003), ao desenvolverem um índice de mensuração da exclusão social. Estes autores pesquisaram o conjunto das 5.507 cidades brasileiras e produziram um mapeamento onde sintetizam que $41,6 \%$ das cidades com maior taxa de exclusão se localizam nas regiões Norte e Nordeste, cidades com uma realidade em 
que se ressalta a pobreza e a fome, população pouco instruída e exercendo trabalhos informais e mal remunerados. Mas salientam os pesquisadores que também se observam excluídos nas cidades do Centro-Sul, embora relativamente escolarizada e com experiência de trabalho assalariada.

Ressalte-se ainda que a desigualdade contemplada no processo de desenvolvimento urbano no Brasil também está hermeticamente estruturada de forma desproporcional em termos de representatividade política. As áreas mais pobres costumam ter uma atenção pouco favorável, sendo comumente retratadas como incubadoras dos problemas que assolam a cidade. Fazendo um paralelo com a ideia desenvolvida pelo sociólogo Zygmunt Bauman (1998) acerca dos parâmetros de ordem e pureza, as áreas periféricas das cidades tomadas de moradias irregulares e espaços insalubres acabam por gerar a sensação de sujeira:

[...] observaremos imediatamente que, entre as numerosas corporificações de
"sujeira" capaz de minar padrões, um caso - sociologicamente falando - é de
importância muito especial e, na verdade, única: a saber, aquele em que são outros
seres humanos que são concebidos como um obstáculo para a apropriada
"organização do ambiente"; em que, em outras palavras, é uma outra pessoa ou,
mais especificamente, uma certa categoria de pessoas, que se torna "sujeira" e é
tratada como tal. (BAUMAN, 1998, p. 17).

A periferia e sua infraestrutura comprometida, as favelas e seus habitantes são vistos por outros grupos de pessoas como turbadores da ordem, da beleza e da limpeza das cidades. Convenientemente, essas pessoas estão devidamente separadas das demais e suas demandas por melhores condições parecem não ser assunto de todos. Pode-se afirmar que o subúrbio é tratado como um estorvo social suportado pelos contribuintes e cofres públicos, espaço de violência que tem localização estratégica. Neste sentido, a canção de Wilson Das Neves (1997, online) descreve:

No dia em que o morro descer e não for carnaval não vai nem dar tempo de ter o ensaio geral [...] O povo virá de cortiço, alagado e favela mostrando a miséria sobre a passarela sem a fantasia que sai no jornal vai ser uma única escola, uma só bateria quem vai ser jurado? Ninguém gostaria que desfile assim não vai ter nada igual.

A ambiência da habitação é basilar em aspectos da formação da imagem que o próprio ser humano constrói de si mesmo e de seu grupo. A promoção de ações que deem acesso a melhores condições de colocação e moradia no espaço urbano alcançam benefícios em termos identitários e culturais. Afinal, convencer alguém que tem ao seu redor uma penosa realidade estrutural, de que é sujeito de direitos e ser humano mencionado e protegido por convenções 
internacionais, é um desafio. O que há no "lixo" senão aquilo que não tem serventia? Carolina (1997, p. 42) expunha suas angústias e suas dificuldades de absorver sua deficiente condição: “[...] cheguei na favela: eu não acho geito de dizer cheguei em casa. Casa é casa. Barracão é barracão".

Para a autora a situação vivida por ela e tantas outras pessoas era incompatível com uma vida razoável. As condições básicas habitacionais não aparecem na sua fala; ela nem mesmo chega a considerar sua moradia como sendo uma "casa". As penúrias que acometiam Carolina, ao contrário do que ocorre com a maior parte das pessoas, lhe possibilitou uma construção ímpar de consciência de sua dura realidade, o que lhe fazia avaliar que nenhum ser humano deveria estar ali, despejado, embora ela e muitos outros estivessem.

\section{ESPAÇO URBANO, IDENTIDADE CULTURAL E DESENVOLVIMENTO}

Observa-se, como foi explicitado na seção anterior, que nas cidades brasileiras a estrutura social marcada por um fosso econômico, educacional e cultural se concretiza na segmentação dos grupos populacionais distribuídos por áreas habitacionais, onde está dada somente para alguns o acesso à educação e às atividades culturais, o que possibilita o acesso aos trabalhos de melhor qualidade e de maior remuneração. Como esclarece Berger (1986), ao descrever a lógica e a dinâmica de funcionamento das modernas sociedades industriais, as classes superiores tendem a possuir as melhores moradias, a escalar o topo do sistema educacional e a ter uma expectativa de vida superior, de tal maneira que as diferentes classes vivem de forma diferente no aspecto quantitativo e quanto ao estilo de vida.

As limitações causadas pela ausência de estrutura pública e a escassez econômica não são os únicos fatores responsáveis pela maneira que vivem os que residem em áreas mais carentes. É preciso considerar também as influências de caráter psíquico que auxiliam na construção da identidade dessas pessoas, e essas razões afluem de diversas direções. Em outras palavras: a forma como as pessoas que residem nas áreas empobrecidas se enxergam e constroem suas identidades é extremamente danosa. Contribui para esse processo os "meios de controle", ou seja, imperativos estabelecidos por grupos na sociedade que funcionam para manter padrões de comportamento conforme as expectativas e interesses do contexto vigente. Tais meios podem ser de cunho legal, moral, econômico e até político (BERGER, 1986). 
Seja na família, no ambiente de trabalho, igreja ou qualquer outro grupo, há forças de controle sendo exercidas sob o sujeito, havendo inclusive sanções no caso de recalcitrância. O empregado punido economicamente pelo patrão, um vizinho que expõe o outro ao ridículo, os pais que menosprezam o filho que ousa pensar diferente, são exemplos de interferências externas que vão sendo introjetadas, por vezes de forma sutil, e que acabam balizando ações como também a forma do indivíduo ver a si mesmo.

As palavras e valores passam a fazer parte do repertório pessoal do sujeito com riscos de serem sedimentados sem nenhuma força de resistência, podendo projetar uma imagem pessoal e coletiva falseada. Em termos de construção da identidade o mundo exterior é fundamental nesse processo. Taylor (1994) esclarece que a identidade cultural resulta da relação com o outro. Destarte, observa-se que pessoas ou grupos, ao serem incorretamente reconhecidas, podem ser estigmatizadas ao ter suas personalidades distorcidas. Isto acontece, por exemplo, quando grupos têm suas imagens desprezadas ou apreendidas como sendo inferiores. Atualmente, no Brasil isso é perceptível quanto aos jovens negros e pardos residentes nas periferias que têm suas imagens generalizadas e confundidas com os de marginais em potencial. Sen e Kliksberg (2010) alertam que, na América Latina, a violência urbana é apreendida com base em alguns mitos que estruturam um complexo processo de criminalização da pobreza, assim condenando comunidades suburbanas à estigmatização.

Com efeito, as elaborações de imagens externas têm papel basilar na construção subjetiva do indivíduo e, para aqueles que se encontram em situação de vulnerabilidade, em função da baixa escolaridade e situação de pobreza, esse processo obstaculiza mais ainda a possibilidade de ascensão social. A repetição de um discurso que não pode ser filtrado pela falta de conhecimento, ignorância ou inocência de alguém é persuasiva tendo em vista a concordância com a vida na prática.

Neste sentido, a Agência Brasil (2015) publicou uma matéria com o seguinte título: "Moradores do asfalto têm visão preconceituosa de favelas, mostra pesquisa". A matéria apresenta informações de um levantamento de dados realizado pelo Instituto Data Popular, que atestou que as comunidades, no senso comum, possuem uma representação que as associam imediatamente a criminalidade. Com efeito, 69\% dos entrevistados afirmaram ter receio de passar nas adjacências de uma comunidade e 51\% atribuem as palavras "drogas" e "violência" de forma imediata quando ouvem falar de favela. 
Faz-se nessa pesquisa a constatação de uma imagem das favelas cada vez mais difundida. Enfim, para quem mora em outras localidades e vive realidades diferentes, as favelas são locais ordinários que estampam os noticiários e obras de ficção - como as novelas - que narram e enfatizam inúmeras adversidades, principalmente as que se referem à episódios de violência. Destarte, o medo e o desconhecimento dificultam a aproximação de outros grupos. Vê-se, então, que a distância entre as classes iniciada por aspectos econômicos ganha o reforço de elementos culturais, em que a ideia de segmentos divididos passa a fazer parte de uma base de valores, crenças e ideais (MARSHAL, 1967).

Assim, a visão de uma pessoa sobre si mesma e a visão exterior a seu respeito compreendem processos sociológicos complexos que atuam de forma categórica na manutenção da própria divisão social e suas manifestações. Outrossim, os meios de controle social distribuídos nos grupos aos quais o indivíduo está ligado contribuem para a manutenção de uma trajetória de vida que dificilmente sairá dos contornos de um determinismo, desestimulando o exercício de esforços de resistência. Como explicita Taylor (1994, p. 43): "a formação da mente humana é, neste sentido, não monológica, não é algo que se consiga sozinho, mas dialógica."

A segregação urbana atua sobre a pessoa como herança histórico-cultural, que a mantem presa num círculo vicioso de reprodução social empobrecida. Portanto, não se resume às questões econômicas os fatores que antagonizam pobres e ricos, na verdade tem-se um fosso entre os habitantes das cidades brasileiras que se mantém em função de um arquétipo que remonta ao colonialismo e ao complexo casa grande e senzala, do período colonial, e ao imperialismo e a estrutura social fundada nos sobrados e mocambos, opondo-se aos trunfos nacionalistas, comumente invocados em períodos eleitorais ou de grandes eventos internacionais - tais como a Copa do Mundo e as Olimpíadas. São evidentes as sutis tentativas de falseamento dessa segregação tóxica que atinge a identidade dos indivíduos, atribuindo um discurso alegórico de pertencimento nacional (FREYRE, 1998; SOUZA, 2009).

A construção da identidade dessas pessoas mais desvalidas deve ser seriamente considerada num âmbito político, pois seus efeitos não orbitam em torno somente da autoestima do indivíduo, eles abrangem também nuances do desenvolvimento de todo um núcleo. Nas palavras de Peter Berger (1986, p. 107), "[...] a sociedade determina não só o que 
fazemos, como também o que somos. Em outras palavras, a localização social não afeta apenas nossa conduta; ela afeta nosso ser."

Porém, apesar da forte influência exterior na formação da subjetividade e o consequente reflexo na trajetória da vida do indivíduo e de sua comunidade, é possível modificar prognósticos. $\mathrm{O}$ aumento de renda e a satisfação de certas necessidades das pessoas que vivem nesses contextos mais carentes não são, em si, suficientes para alavancar as mudanças que possibilitem a ruptura do círculo vicioso da reprodução social empobrecida, fazem-se necessárias mudanças mais aprofundadas. Nesse sentido, o acesso à informação e a conscientização da importância das liberdades políticas são essenciais para a construção de mudanças desse matiz. O asfalto na rua, o saneamento adequado, a criação do conjunto habitacional, proporcionam a redução de uma série de privações, mas ações como essas devem estar acompanhadas de esforços para que sejam trabalhadas as perspectivas coletivas dessas pessoas.

O desenvolvimento urbano tem sua gênese no desenvolvimento humano. Pessoas com capacidade de escolha livre e consciente e que interagem politicamente podem gerar efeitos identitários geracionais na construção de muitos "eu's" e "nós" sob contingências mais esperançosas. Na perspectiva do senso comum, quando se menciona "desenvolvimento", a ideia inicialmente projetada é a de acesso à bens, tecnologia, conforto ou necessidades básicas atendidas. No entanto, o desenvolvimento, quando refletido para além do âmbito financeiro, se refere a um tipo de evolução que se inicia num plano interno.

É correto relacionar o desenvolvimento com a prosperidade financeira de uma comunidade, mas é reducionista associá-lo somente à renda e ao poder de compra. Como chama a atenção Amartya Sen (2010, p. 29): "o desenvolvimento tem de estar relacionado sobretudo com a melhora da vida que levamos e das liberdades que desfrutamos". A questão a ser entendida é que, na contramão da cultura de consumo a qual estamos submetidos imperiosamente, a mensuração do desenvolvimento deve considerar as liberdades políticas e os direitos fundamentais disponíveis e acessíveis de uma sociedade, que, por sua vez, instrumentalizam outras liberdades.

É sabido que privações econômicas podem restringir pessoas de terem uma vida mais confortável, e é uma realidade nos chamados países periféricos e semiperiféricos (SEN, 2010). No Brasil, país à margem do núcleo orgânico produtor de tecnologia, marcado por uma ferrenha distribuição desigual da riqueza produzida, as privações econômicas são 
alarmantes e alcançam inumeráveis pessoas no campo e, sobretudo, nas cidades. Neste sentido, aduz Milton Santos:

Com diferença de grau de intensidade, todas as cidades brasileiras exibem problemáticas parecidas [...] problemas como emprego, da habitação, dos transportes, do lazer, da água, dos esgotos, da educação e saúde são genéricos e revelam enormes carências [...] (SANTOS, 2013, p. 105)

Uma reflexão apressada pode conduzir ao entendimento de que é supérfluo a reivindicação de liberdade política quando são prementes as necessidades básicas. Entretanto, é plausível a concepção de que a liberdade é fator decisivo para o enfrentamento das causas determinantes da escassez dos bens materiais e imateriais que condicionam a pobreza e a miséria. Isto porque a participação política efetiva é o elemento fundante da formação de valores que viabilizam as escolhas conscientes. Não é exagero afirmar que, por intermédio da participação popular, fermentam-se as condições que tornam possível a execução de ações governamentais geradoras da capacitação dos indivíduos para que transponham os obstáculos ao seu desenvolvimento (SEN, 2010).

As cidades também revelam, visualmente, privações de liberdades das pessoas residentes em áreas suburbanas, e não estamos nos referindo às eventuais restrições causadas pelo aumento da violência, mas sim à ausência de um ponto de luz sob os problemas de quem vive "à margem". Assim, na medida em que as demandas de um grupo não são consideradas, as suas reais necessidades também não são compreendidas. Neste sentido, White (2005), relata sua experiência de "observação participante" em Corneville, distrito de North End em Boston. Segundo o autor, não há como saber a fundo questões de relevância local através de uma análise superficial:

A única maneira de obter esse tipo de conhecimento é viver em Corneville e participar das atividades de sua gente. Para quem faz isso, a área se revela sob uma luz totalmente diferente. Prédios, ruas e becos que antes representavam destruição e aglomerado físico passam a formar um panorama familiar para os atores da cena cornevilliana (WHITE, 2005, p. 20).

O autor explicita que uma visão fiel de contextos das áreas estudadas só pode ser retratada mediante um observador "participante" ou alguém que esteja ambientado com os pormenores do local, como seus próprios moradores. Por isso é tão importante dar "voz" à essas pessoas, pois elas podem expor de forma realista as necessidades e as demandas inerentes à sua conjuntura. Essa atitude não se relaciona com as estratégias de marketing comumente usadas por candidatos em períodos eleitorais, que entram nas comunidades, 
sobem os morros e não se comprometem em atuar em prol daquela camada. Essas figuras eram conhecidas no "Quarto de despejo" de Carolina, que ao longo de suas narrativas expõe o oportunismo dos políticos em relação aos pobres:

[...] Quando um político diz nos seus discursos que está ao lado do povo, que visa incluir-se na política para melhorar as nossas condições de vida pedindo nosso voto prometendo congelar os preços, já está ciente que abordando este grave problema ele vence nas urnas. Depois divorcia-se do povo. Olha o povo com os olhos semicerrados. Com um orgulho que fere a nossa sensibilidade. (JESUS, 1997, p. 34).

Em sociedades complexas e heterogêneas é fundamental que haja arranjos institucionais que viabilizem a oitiva dos segmentos populacionais. No Brasil, há instrumentos de participação popular que propiciam visibilidade às mais diversas demandas na ocasião do planejamento urbano municipal. Os artigos 29, inciso XII da Constituição Federal e $2^{\circ}$, inciso II da Lei 10.257/2001 (Estatuto da Cidade) são exemplos disso. O chamamento de grupos representativos da sociedade civil é primordial para que sejam apuradas e reveladas as suas necessidades para maior embasamento e efetividade das políticas públicas. Cumpre frisar que a própria inclusão dos artigos 182 e 183 na Constituição, que tratam da Política Nacional de Desenvolvimento Urbano, foi fruto de mobilização social encabeçada pelo Movimento Nacional pela Reforma Urbana (BRASIL, 1988, 2011; LOPES, 2005).

Convém ressaltar que a participação popular através do planejamento municipal e a ação dos movimentos sociais são possíveis dentro de um contexto democrático que, ao contrário de sistemas autoritários, permite a liberdade de expressão e a fluência de direitos fundamentais. A Democracia é um ambiente profícuo em termos de desenvolvimento humano real, pois é o cenário político que permite, pelo menos em termos ideais, a coexistência de vontades populares divergentes, alternância de poder e transparência nos processos decisórios. Só a Democracia permite a influência aberta das minorias políticas que não exercem circunstancialmente o poder (BOBBIO, 1997).

Portanto, não se pode falar em "cidade desenvolvida", "país desenvolvido" ou "sociedade desenvolvida" se não há respeito às liberdades e aos direitos, se não há oportunidades de expressão de demandas específicas, se as decisões políticas não são claras quanto ao direcionamento de investimentos que, por vezes, miram apenas no bem-estar de uma parte da sociedade. Ao desconsiderar o que um segmento social tem a expor, negamos o seu reconhecimento. Por fim, viu-se aqui que música e escrita podem revelar necessidades e 
insatisfações, podem revelar também críticas ao poder público e a outros grupos sociais. Diante disso é necessário que a cultura de massas, as expressões oriundas das comunidades sejam observadas e pautadas.

Carolina Maria, enquanto observadora participante, descreveu também seus sentimentos. Vê-se isso quando narra episódio em que buscou assistência do poder público. A fala da autora denota reprovação com a forma como as pessoas em condição de pobreza são tratadas:

Para não ver meus filhos passar fome fui pedir auxílio ao propalado Serviço Social. Foi lá que eu vi as lágrimas deslizar dos olhos dos pobres. Como é pungente ver os dramas que ali se desenrola. A ironia com que são tratados os pobres. A única coisa que eles querem saber são os nomes e os endereços dos pobres. (JESUS, 1997, p. 37).

Expressa aí a autora toda a dificuldade que envolve a busca de atenção institucional por aqueles que, justamente, são carentes dessa atenção e justificam a existência do serviço público. Como gerar expectativas de participação popular desses segmentos, se a exclusão se opera até mesmo nos serviços públicos direcionados para os mais carentes? Mais do que isso, como esperar que esses segmentos, marcados por uma construção identitária deformada, consigam se colocar e participar do processo de construção de políticas públicas essenciais?

\section{CONCLUSÃO}

A segregação urbana é a representação visível de toda uma estrutura social marcada por fendas profundas com gênese histórica. As desigualdades entre as pessoas que residem em uma mesma cidade são muitas e vão desde as condições estruturais do lugar onde vivem até o nível de visibilidade política de seus grupos.

As cidades carecem sim de intervenções de democratização do uso do solo urbano, de forma que todos possam ter o adequado acesso aos serviços públicos básicos. No entanto, o desenvolvimento urbano não tem seu fim em obras de melhorias estruturais, ele está intimamente ligado aos esforços paralelos no sentido de desenvolver seus habitantes.

Esse desenvolvimento subjetivo se dá pela afluência de elementos geradores de liberdades e de direitos, capazes de fomentar um ambiente propício à formação das identidades participativas e ativas na construção de suas trajetórias de vidas cidadãs. 
Demonstra-se nociva a forma como a imagem da periferia tem sido retratada, imagem esta que altera a concepção que as pessoas do próprio lugar têm de si mesmos.

Carolina Maria de Jesus relata as privações causadas pela omissão do Poder Público em relação à favela onde morava, mas também exibe a forma com que era tratada por burlar a desesperança pulverizada em sua comunidade. Era ridicularizada por apreciar escrever e ler, hábitos simples, mas que pareciam impróprios para alguém de seu perfil.

As melhorias materiais urbanas são urgentes, assim como os investimentos no capital humano. O que distancia os estratos sociais no Brasil extrapola a questão da renda, do asfalto, das cercas e muros, o abismo maior a ser encarado está na forma como uns enxergam os outros. A obra de Carolina canalizou e expôs, em formato literário, as necessidades e apuros vividos por estas pessoas que são preteridas nos planos políticos e econômicos. A autora demonstrou que a cidade é também espaço de afetos, além de abrigar pessoas em grupos compartimentados, delimitados por condições socioeconômicas. A superação dessa estrutura apartada é um desafio que impõe a necessidade de enfrentamento de forças culturais históricas.

\section{REFERÊNCIAS}

ALVES, Francisco. Favela. [S. 1: 1936]. 1 vídeo (3 min. 01 seg.). Publicado pelo canal Eduardo Paz Fraga. Disponível em: 〈https://www.youtube.com/watch?v=wsVLvE1hi9w〉. Acesso em: 29 ago 2019.

BARIFOUSE, Leonardo. O planejamento urbano entre a ordem e o caos. Revista de Direito da Cidade. v. 5, n. 1, 2013, pp. 146-169. Disponível em: <https://www.epublicacoes.uerj.br/index.php/rdc/article/view/9727/7626>. Acesso em: 21 ago. 2019.

BAUMAN, Zygmunt. O mal-estar da pós-modernidade. Tradução de Mauro Gama e Cláudia Martinelli Gama. Rio de Janeiro: Zahar, 1998.

BERGER, Peter L. Perspectivas sociológicas: uma visão humanística. Tradução de Donaldson M. Garshem. 12.ed. Petrópolis: Vozes, 1986.

BOBBIO, Norberto. O futuro da Democracia; uma defesa das regras do jogo. Rio de Janeiro, Paz e Terra, 1997.

BRASIL. Constituição (1988) Constituição da República Federativa do Brasil. Texto constitucional promulgado em 5 de outubro de 1988. Brasília, DF, Senado, 1998. Disponível em: < http://www.planalto.gov.br/ccivil_03/constituicao/constituicaocompilado.htm>. Acesso em 21 ago. 2019. 
BRASIL. Lei n. 10.257 de 10 de julho de 2001. Regulamenta os arts.182 e 183 da Constituição, estabelece as diretrizes gerais da política urbana e dá outras providências. Brasília, DF, 10 jul. 2001. Disponível em:

<http://www.planalto.gov.br/ccivil_03/leis/leis_2001/110257.htm>. Acesso em: 07 maio 2019.

DAS NEVES, Wilson; PINHEIRO, Paulo César. O dia que o morro descer e não for carnaval. [S.l.], [S.n.]: 1997. 1 vídeo (4 min. 33 seg.). Publicado pelo canal Guilherme Araujo Gonçalves. Disponível em: 〈https://www.youtube.com/watch?v=mr0ZUETRnJk>. Acesso em: 20 ago. 2019.

DOMINGUINHOS; NILO, Fausto. Pedras que cantam. [S.1.]: [S.n.], 1991. Disponível em: <http://www.fagner.com.br/>. Acesso em 16 jun 2018.

FREYRE, Gilberto. Sobrados e Mucambos. São Paulo: Record, 1998.

GANDRA, Alana. Moradores do Asfalto têm visão preconceituosa de favelas, mostra pesquisa. Agência Brasil [site]. Rio de Janeiro, 16 fev. 2015. Disponível em: $<$ http://agenciabrasil.ebc.com.br/geral/noticia/2015-02/moradores-do-asfalto-tem-visaopreconceituosa-em-relacao-favelas> . Acesso em: 09 jun. 2018.

GOHN, Maria da Glória. 500 anos de lutas sociais no Brasil: movimentos sociais, ONGs e terceiro setor. Revista Mediações. Londrina, v. 5, n. 1, p. 11-40, jan-jun 2000. Disponível em: <http://www.uel.br/revistas/uel/index.php/mediacoes/article/view/9194>. Acesso em: 20 de maio de 2018.

GONÇALVES, Marco Antônio. Um mundo feito de papel: sofrimento e estetização da vida (os diários de Carolina Maria de Jesus). Horizontes Antropológicos. Porto Alegre, ano 20, n. 42, pp. 21-47, jul-dez 2014. Disponível em: 〈http://www.scielo.br/pdf/ha/v20n42/02.pdf〉. Acesso em: 28 ago. 2019.

LOPES, Ana Elvira Barros Ferreira. O Direito que nasce da luta: do movimento nacional pela reforma urbana à moradia como direito fundamental no Maranhão. II Jornada Internacional de Políticas Públicas. 2005, São Luís. Disponível em:

<http://www.joinpp.ufma.br/jornadas/joinppIII/html/Trabalhos2/Ana_\%20Elvira\%20Barros\% 20Ferreira\%20Lopes214.pdf >. Acesso em: 15 nov. de 2018.

JESUS, Carolina Maria de. Quarto de Despejo. São Paulo: Editora Ática S. A., 1995.

MARICATO, Hermínia. Metrópole, legislação e desigualdade. Estudos Avançados, v. 15, n. 48, 2003, pp.151-166. Disponível em: 〈http://www.revistas.usp.br/eav/article/view/9928>. Acesso em: $1^{\circ}$ maio 2019.

MARSHAL, T.H. Cidadania, Classe social e status. Tradução de Meton Porto Gadelha. Rio de Janeiro: Zahar Editores, 1967. 
MOREIRA. Adelino. Deusa do asfalto. [S.l: 1958]. 1 vídeo (3 min. 6 seg.). Publicado pelo canal Roberto Margato de Castro. Disponível em:

<https://www.youtube.com/watch?v=Y9NiTRBtweM>. Acesso em: 29 ago. 2019.

POCHMANN, Marcio e AMORIM, Ricardo. Atlas da exclusão social no Brasil. São Paulo:

Cortez, 2003.

SANTOS, Milton. A urbanização brasileira. 5. ed. São Paulo: edUSP, 2013.

SEN, Amartya; KLIKSBERG, Bernardo. As pessoas em primeiro lugar: a ética do desenvolvimento e os problemas do mundo globalizado. São Paulo: Companhia das Letras, 2010 .

SEN. Amartya. Desenvolvimento como liberdade. Tradução de Laura Teixeira Motta. São Paulo: Companhia das Letras, 2010.

SOUZA, Jessé. Ralé brasileira: quem é e como vive. Belo Horizonte: Editora UFMG, 2009.

TAYLOR, Charles. Multiculturalismo. Tradução de Marta Machado. Lisboa: Instituto Piaget, 1994.

VILLAÇA, Flávio. Reflexões sobre as cidades brasileiras. São Paulo: Nobel, 2012.

WHYTE, William Foote. Sociedade de Esquina. Tradução de Márcia Lúcia de Oliveira. Rio de Janeiro: Jorge Zahar Ed., 2005. 